\title{
Developing knowledge work skills in a university course
}

Sansone, N. ${ }^{\text {a* }}$, Cesareni, D. ${ }^{\mathrm{b}}$, Ligorio, M.B. ${ }^{\mathrm{c}}$, Bortolotti, I. ${ }^{\mathrm{d}}$ and Buglass, S. L. ${ }^{\mathrm{e}}$

${ }^{a, b, d}$ Department of Social and Developmental Psychology, University La Sapienza, Rome, Italy; ${ }^{c}$ Department of Educational Sciences, Psychology and Communication, University of Bari “Aldo Moro”, Bari, Italy

a* Via dei Marsi, 78, 00185 Roma RM, Italy, ORCID 0000-0002-3413-7983

nadia.sansone@uniroma1.it;

${ }^{\mathrm{b}}$ Via dei Marsi, 78, 00185 Roma RM, Italy, ORCID 0000-0002-8485-8498

donatella.cesareni@uniroma1.it;

${ }^{c}$ Via Scipione Crisanzio, 42, 70122 Bari BA, Italy, ORCID 0000-0003-3028-5046

d Via dei Marsi, 78, 00185 Roma RM, Italy, ORCID 0000-0002-3271-5989, ilaria.bortolotti@uniroma1.it

${ }^{e}$ Department of Psychology, Nottingham Trent University, 50 Shakespeare Street, Nottingham, NG1 4FQ, UK, ORCID 0000-0002-1079-8461 sarah.buglass@ntu.ac.uk

Nadia Sansone is a PhD student at the Department of Social and Developmental Psychology of University La Sapienza. Her main research interests are in the field of Educational Technology and Collaborative Learning, with a specific focus on Higher Education. She has participated in various national and international projects around this topic (PRIN 2005; KNORK 2014-2016; HORIZON 2020 Up2U 2017-2019) in which she has led teachers' training programs, designed and conducted research studies, and published several international articles, chapters and conference papers. Since 2014 she has been an e-Learning consultant for the School of Administration of the Italian Presidency of the Council of Ministers. She is the Chief Editor of "QWERTY, International Journal of Technology, Culture and Education". 
Donatella Cesareni is Associate Professor of Experimental Pedagogy at the Faculty of Medicine and Psychology, where she teaches Experimental Pedagogy and is a member of the $\mathrm{PhD}$ programme in "Social Psychology, Development and Research." She has developed research in the field of Education Technologies and has collaborated on national and international research to monitor the collaborative use of technology at school (COFIN 2000; PRIN 2005; European Projects CL-net, Computer supported collaborative learning networks, 1998-1999, Euroland, 1999-2000 and ITCOLE, Innovative Technology for Collaborative Learning and Knowledge Building, 2001-2003, KNORK 2014-2016). She was involved in teacher training for new technologies, also collaborating with INDIRE for some on-line training courses (For-tic project). Donatella is the co-editor of "QWERTY, International Journal of Technology, Culture and Education" and is part of the scientific committee of the scientific journal "TD, Didactic Technologies".

Maria Beatrice Ligorio is a Professor at the University of Bari (IT), Department of Educational Sciences, Psychology and Communication where she teaches Educational Psychology and Elearning. Her research interests concern new educational technology, digital identity, learning in virtual environments, Educational web- forums, communities, intersubjectivity, higher education, innovative learning methods, blended learning and e-learning. She has published over 80 research papers, has contributed to many books and has led numerous international research projects, predominantly focused on the use of technology in educational contexts. She is the main editor of the international journal "QWERTY, International Journal of Technology, Culture and Education" (http://www.ckbg.org/qwerty)..

Ilaria Bortolotti is a PhD student in the Department of Social and Developmental Psychology at the University La Sapienza. She is a qualified psychologist, instructor and e-tutor for several University and teacher training courses. Her research interests are in education, technology mediated collaborative learning and teachers' training. Ilaria is a member of the Collaborative 
Knowledge Building Group and has participated in international projects including KNORK and Up2U as a Consortium GARR fellowship student.

Sarah L. Buglass is a Senior Lecturer in Psychology at Nottingham Trent University where she teaches on both undergraduate and post-graduate psychology courses. Her research interests combine the domains of social, developmental and cyber psychology. She has published research in international journals on social interactions on digital platforms, online vulnerability, social network analysis and the fear of missing out (FOMO). 


\section{Developing knowledge work skills in a university course}

In this paper, we present a blended university course whose design is inspired by the Trialogical Learning Approach and its six Design Principles. The structure, activities, and content of the course are described in detail. The course description is followed by an explorative case-study conducted on data collected during the 2017-2018 edition of the course. The general aim was to understand the impact of the course on students' perceptions of their acquisition of knowledge work skills and on their overall appreciation of the course. One hundred and nine psychology students ( 27 male, 82 female, aged 20-23 years) voluntarily participated in a course titled 'Experimental Pedagogy' held at Sapienza, University of Rome (IT). The data collection was informed by the trialogical design principles that inspired the course and defined the knowledge work skills to be observed, i.e. collaboration, continuous improvement, and digital skills. Two self-report anonymous questionnaires were administered; one was completed at the end of the course and one at the end of each of the three modules composing the course. Data was analysed using a mixed-methods (qualitative and quantitative) approach. Results indicated that the course was perceived to effectively promote the majority of the intended skills. Moreover, students appreciated the possibility to concretely work on a project-based learning activity that allowed them to create a shared and meaningful object and reflect their actual learning as intended by the theoretical approach.

Keywords: knowledge-work skills; Higher Education; technology-enhanced learning; Trialogical Learning Approach

\section{Theoretical introduction: skills and education for a knowledge work society}

One of the main goals of secondary and higher education is to ensure that students acquire useful skills to achieve success not only in their studies, but also in their future career and in life in general. In every age, the "useful skills" are defined according to the context in which these skills should be mobilised (Le Boterf 1994). The context in which today's students live and work is that of a highly technological knowledge work society. In other words, it is a society where knowledge and technology represent two 
"inextricably linked" factors in any educational and professional context (Scardamalia, Bransford, Kozma, and Quellmalz 2012, p. 234). To be successful in such a society, students should learn to act and work intentionally and effectively, individually or together with others, in authentic contexts, solving complex problems and creating new solutions and new knowledge. Based on these aspects, the knowledge work skills that students should master can be grouped into three categories (Ilomäki, Lakkala, and Kosonen 2013): individual (e.g., metacognitive skills, creativity, and ICT skills), social (e.g., networking and communications) and epistemic (e.g., critical thinking, information management, and networking).

As highlighted by the international economic community, supporting the development of these knowledge work skills signifies a need for educational agencies to review curricula and pedagogical practices (OECD 2013). Through specific learning strategies, students should become able to act and work in constantly changing situations (Biesta 2011), in an uncertain world and unknown future, facing incomplete and imperfect results (Aggarwal 2011; Biesta 2009; Johansson, Kopciwicz, and Dahlgren 2008), and carry forward a reflexive attitude oriented towards life-long learning (Delors 1997). In this direction, over the last four years, we have designed and tested a university course in which students are involved in concrete activities that allow them to truly collaborate to create knowledge and build meaningful artifacts, while developing key competencies for their academic and professional careers (Sansone, Cesareni, Bortolotti, and McLay submitted).

The course design is inspired by the Trialogical Approach to Learning (TLA, Paavola, Engeström, and Hakkarainen 2012). The approach is "Trialogical" in the sense that it integrates "monological" and "dialogical" approaches to learning with a third element: the intentional processes involved in the collaborative creation of meaningful 
and useful knowledge artifacts. These objects are not merely conceived and realised for evaluation purposes, rather they are meant to be concretely used, be it inside or outside the learning community which created them. In this approach, therefore, the acquisition and participation metaphors of learning (Sfard 1998) are embedded in the knowledge creation metaphor, going beyond two traditional dichotomies: individual versus social processes, and conceptual knowledge versus social practices, needed to foster collaborative creativity (Paavola, Lipponen, and Hakkarainen 2004).

The Trialogical Approach is applied through six Design Principles (DPs) (Hakkarainen and Paavola 2009; Paavola and Hakkarainen 2014). These principles guide the planning of technology-based teaching and learning activities to facilitate the shared efforts of working with knowledge artifacts, thus supporting the development of the related knowledge work skills (Paavola et al. 2011) (see Table 1).

[Table 1. The six design principles (DPs), near here]

Together, the six principles synthesise the main pillars of the TLA: designing object-based learning activities through which to enhance both individual and collaborative work strategies, creative processes, and an effective use of educational technologies. In this sense, the Trialogical Approach is not new. However, it provides teachers and researchers with precise guidelines that enable them to innovate their pedagogical practices and inspire the use of broader and consolidated theoretical frameworks such as Learning by Doing (Dewey 1904; Kolb 1984), the Cultural Historical Activity Theory (Engeström 1987) and the Knowledge Building Theory (Scardamalia and Bereiter 1994, 2003).

The remaining sections of this paper, will on the one hand, show how the Trialogical Learning Approach and its six principles have inspired a blended university 
course and have been concretely defined through specific learning strategies and techniques. On the other hand, the paper will demonstrate how the same principles have been used as an analytic lens to examine the course through specific data-collection tools designed around them. Therefore, in the present paper the TLA has served as both a theoretical framework and as a means of providing methodological support.

\section{Objectives and research questions}

The explorative case-study presented aims to inform on the innovative pedagogical practices that were adopted in a blended university course by reporting on the observed impact on students' perceptions of knowledge-work skills and on their appreciation of the course. Therefore, firstly we will describe in detail the course inspired and shaped around the TLA principles. Secondly, to examine the course impact, the following specific research questions will be addressed:

Research Question 1 (RQ1): To what degree do students believe they have acquired specific knowledge work skills at the end of the course?

Research Question 2 (RQ2): To what degree do students believe they have acquired specific knowledge work skills in relation to each specific module of the course? Research Question 3 (RQ3): Which aspects did the students appreciate the most during each module of the course?

\section{Participants and context}

One-hundred and nine psychology students (27 male, 82 female, aged 20-23 years) voluntarily participated in an undergraduate course titled 'Experimental Pedagogy', offered at the University of Rome (Italy). The aim of the course was to provide fundamental knowledge about main learning theories and authors, and to let students experience specific collaborative techniques and an educational use of modern 
technologies. Students were divided into 11 learning groups with a minimum of nine and a maximum of 11 participants in each. The course lasted three months and was organised into three consecutive modules, each with a duration of four weeks. Each module addressed a different part of the curriculum (learning and instruction theories; collaborative learning; and technology-based learning) but followed a similar structure. In each module the learning groups had to analyse and discuss issues raised during faceto-face encounters, study the learning material provided by the teachers, reflect upon the various topics, search and share theoretical insights connected to the course content, build collaborative products, and reciprocally comment on them by providing formative feedback. At the end of each module, students were asked to respond to a SelfMonitoring questionnaire. In addition, individual participation in the activities was assessed by the teacher and collectively discussed. The following table (Table 2) summarises the activities students performed in each module.

[Table 2. The activities in the three modules, near here]

As the architecture of the course was inspired by the Trialogical Approach, each of the six Design Principles inspired specific course activities and, vice versa, each activity followed a specific principle. Following DP1, the meaningful object to be created by each learning group was a pedagogical scenario that incorporated the use of technologies in collaborative learning activities and was meant to be implemented at a school or at university. At the end of the first two modules, each learning group had to create preliminary collaborative products: a) a conceptual map concerning the figure of the "good teacher"; and b) a power point presentation of the first draft of the pedagogical scenario, focusing on the basic theoretical references. These two products 
preceded the creation of the final document describing the pedagogical scenario. Together, the objects requested allowed the learning groups to plan specific tasks around concrete activities (Dewey 1904; Kolb 1984), externalising students' conceptual efforts and the cultural practices of the learning community (Bruner 1996).

For DP2, students were required to work in groups, both face-to-face and online. To fruitfully integrate individual and group activities it is necessary to sustain both responsibility for one's own learning as well as for peers' learning (Slavin 2010; Wenger, Trayner, and De Laat 2011). Opportunities for real collaborative learning, in fact, depend on structured and carefully planned intra-group interactions (Dillenbourg and Hong 2008), anchored to precise pedagogical models and using accurate collaborative scripts, such as the Role Taking Strategy (De Wever et al. 2010; Strijbos and De Laat 2010). Many roles can be organised around specific tasks in order to: a) support constructive interaction and facilitate learning (Topping 2005), b) stimulate group cohesiveness and sense of responsibility towards group work (Mudrack and Farrell 1995), and c) support coordination within the groups (Johnson, et al. 1992).

In our course, students in turn had to cover specific roles that were meant to integrate individual and collaborative learning, and sustain personal and collective agency and responsibility. The roles were: a) the social tutor (task: promoting his/her own group participation); b) the synthesiser (task: writing a weekly summary of the group discussion); c) the sceptic (task: presenting alternative points of view to "warm" the discussion); d) the individual responsible for the collaborative artifact (task: arranging tools and materials for the classroom collaborative activity of building the artifact); e) the researcher (task: searching for further materials to improve the discussions); f) the process observer (task: producing a critical report of his/her own group work in the module); and g) the reviewer (task: collecting peer and experts' 
feedback to help his/her own group in the final revision). The use of these roles is the result of a decade of testing within similar courses (Cesareni, Cacciamani and Fujita 2016; Ligorio and Sansone 2009; Sansone, Ligorio, and Buglass 2016), in which they have been shown to stimulate responsibility as well as specific knowledge work skills. Interaction between groups was supported during classroom presentations of the groupwork and by the peer-review sessions, aimed at improving the intermediate products. Details of these interactions are described as follows.

Following DP3, long-term processes of knowledge advancement were supported by the modular structure of the course and by the use of focused learning discussions among peers (Webb 1985). Peer discussions are considered to be less rhetorical than those that occur between teachers and students, which are often shaped in the form of an evaluation test in which students do not express themselves, rather they try to guess the answers teachers are expecting (Cazden and Beck 2003; Mehan, 1979). Questions from peers, instead, tend to be authentic and are meant to clarify and better understand a concept (Choi, Land, and Turgeon 2005; Rubin et al. 2008). It is this feature that makes structured discussions the basis for a real knowledge building community in which students are engaged to improve the existing theories, by exchanging their views and critically challenging the authoritative sources (Scardamalia and Bereiter 2007). Moreover, digital environments such as the web-forum used in this course (see DP6) support knowledge building discussion since they make students 'ideas visible and thus easily improvable (Scardamalia 2004).

In each module, therefore, students were asked to discuss specific topics and compare their views with each other and with sources provided from the teacher. In line with DP3, the groups' products were continuously put under revision and improved based on the reciprocal suggestions. A specific procedure was followed to meet this 
aim: each group was asked to review the products created by the other groups, define the appropriate criteria for assessing them, and, for each criterion, provide a score and formative advice to improve the products. In the subsequent group activity, each group read the reviews provided by the other groups and, based on them, could work to improve their own products. This sequence of activities (artifact creation, peer-review, artifact improvement) was iteratively repeated in each of the three modules, with the aim of improving students' ability to critically evaluate their own and their colleagues' learning output, thus developing better reflective competencies (Kong 2014; Nicol, Thomson, and Breslin 2014).

In line with DP4, various forms of knowledge and knowledge-practices were introduced: brainstorming, representation of concepts through conceptual maps, reading and commenting on academic articles, and knowledge building discussions. Moreover, individual and collective reflection on the learning process was repeatedly solicited through group discussion about the teacher's evaluation at the end of each module, and the critical report compiled by the process-observer of the group-work and made available to his/her own group.

For DP5, students are supposed to interact with practices and methodologies typical of other communities. In our case, the community students referred to was a school, with students using learning-design-related practices that lead to the creation of a pedagogical scenario which was meant to be implemented in a real classroom. This activity was supported by a guiding template, provided by the teacher of the course, that aimed to make more visible the crucial aspects to consider when planning a learning course (e.g., learning goals, sequence of the activities, evaluation, tools, etc.). Furthermore, when involved in the peer-review sessions, students had to establish appropriate criteria and to use them accordingly, simulating typical teaching practice. 
Finally, when writing the pedagogical scenario, each group could refer to an expert, namely a school or university teacher, who in the role of a supervisor was willing to provide suggestions and/or in-depth information and clarifications.

DP6 states the importance of providing flexible mediation tools to support the learning activities. Based on Vygotskij (1981), who argued that the experience of the world is always mediated by a tool, whether tangible or intangible, knowledge is here perceived as a collaborative construction mediated by cultural and social artifacts and grounded on practical activities (Cole 1996). Therefore, technology should be used to create, share, elaborate, transform, and organise different artifacts; as well as to make visible, reflect on and support the evolution of the related knowledge practices. The online activities of the course occurred in the Moodle (Modular Object Oriented Dynamic Learning Environment) platform ${ }^{1}$. Moodle is a flexible Learning Management System that provides traditional educational tools (e.g., course management, assessment tests, and exercises) along with interactive tools, such as chats, forums, and wikis, thus supporting a constructivist educational approach. Each of the 11 groups had its own dedicated virtual space - namely a Moodle course page - where they could discuss, add links to external resources, upload documents, share collaborative products, and much more. In addition, each course page included links to tools such as Padlet $^{2}$ (for brainstorming activities), Google drawings (to create online conceptual maps), and Google documents (for the collaborative writing of the pedagogical scenario). The result offered a rich virtual environment to the students, composed of a series of different tools that were able to cover their different needs and support the several proposed activities.

\footnotetext{
${ }^{1} \mathrm{http} / / /$ elearning.uniroma1.it

${ }^{2}$ Padlet.com
} 


\section{Method}

\section{Measurement tools}

To answer the research questions, two self-report anonymous questionnaires were administered to the students:

- The Contextual Knowledge Practice questionnaire (CKP, Muukkonen et al. 2017) which was administered at the end of the course. The CKP comprises of 27 Likert-scale items, which are organised into seven scales built around TLA design principles. Each of the seven scales corresponds to specific knowledgework skills: a) Learning to collaborate on shared objects (related to DP1); b) Integrating individual and collaborative work (related to DP2); c) Improving objects through feedback (related to DP3 and DP4); d) Continuously developing knowledge objects (related to DP4); e) Understanding various disciplines and practices (related to DP5); f) Interdisciplinary collaboration and communication (related to DP5); and g) Learning to exploit technology (related to DP6).

Students were asked to declare to what extent (1: not at all -5 : very much) they perceived themselves to have acquired the related skills at the end of the course (RQ1).

- $\quad$ The Self-Monitoring questionnaire (SM) was filled in at the end of each module. Designed to complement the CKP questionnaire, the SM is a semi-structured tool that aims to collect: a) students' perceptions about the development of specific knowledge work skills, and b) personal feedback about the learning activities - collected through an open-ended question ("What did you appreciate the most in the module just ended?"). The SM was conceived and used as an ongoing data-collection tool, providing actual and detailed information about 
each of the three modules completed during the TLA inspired course. Due to the specificity of the modules' structure, we wanted to explore if the modules affected students' perceptions in different ways, thus providing information on what and how to improve the learning activities. Moreover, in line with DP4, the SM-questionnaire was meant to trigger an ongoing reflection about one's own learning, whilst being able to sustain students' self-monitoring and allow them to adjust their participation strategies. Based on these aspects, the 18 items composing the tool refer to module-related abilities (for instance, To search information from the internet, and To properly use theoretical references).

Considered together, the two tools (CKP and SM) provided a means of evaluating the extent to which the Trialogical principles could be used to observe, analyse and refine the TLA inspired course.

\section{Data analysis}

The data collected included:

- $100 \mathrm{CKP}$-questionnaire responses $(91.7 \%$ of the 109 participants registered on the course);

- 303 SM-questionnaire responses $(92.7 \%$ of the 327 expected responses, over the three modules).

SPSS was used to perform significance tests (ANOVA) on the closed items.

The open question was analysed through content analysis, which led to the construction of a codebook composed of categories informed by the Trialogical approach. The content analysis followed three stages:

1) the answers were read to extract preliminary categories based on the theories that inspired the course; 
2) each student response was segmented into units of analysis and categories. A unit of analysis was considered a 'unit of meaning' (Chi 1997), in that one or more sentences were referring to the same meaning. Student responses could contain multiple segments, reflecting the different units of analysis present in their response. Following the segmentation, units of analysis were considered and assigned a single category based on the general meaning that they expressed. This ensured that individual students were not counted multiple times for one category;

3) the categories were better defined, and a new codification of each segment was performed.

Table 3 reports the total number of answers collected and the extrapolated units of analysis.

[Table 3. Segmentation of the answers in each module, near here]

In Table 4 the codebook generated at the end of the procedure is presented.

[Table 4. Codebook for the content analysis of the open-question "What did you appreciate the most in the module just ended?", near here]

Following, an example of segmentation by unit of analysis and category assignment is provided.

Module 1. Question "What did you appreciate the most in the module just ended?" -

"I appreciated the possibility we were given to express our thoughts on a particularly important topic and to listen to other points of view [unit of analysis 1, category Debate and exchange]. Moreover, I was able to deepen my knowledge just thanks to the communication with other participants of my group" [unit of analysis 2 , category Knowledge Building]. 
Throughout the coding process, two researchers worked independently. At the end of the first phase, they compared their outcomes and a 10\% discrepancy was found. The controversial cases were discussed with a third researcher until 100\% agreement was reached.

\section{Results}

The general aim of the paper was to consider the impact of a university course inspired by the TLA on the students' perceptions and points of view about the skills they believe themselves to have learnt, and on their overall appreciation of the course architecture. In this section, answers to the questions guiding our research are reported.

\section{The knowledge work skills perceived as most acquired at the end of the course}

To investigate research question 1 (RQ1), namely "To what degree do the students believe they have acquired specific knowledge work skills at the end of the course", responses to the CKP-questionnaire were analysed. The results allowed us to capture students' comprehensive perceptions of the skills they had developed over the duration of the ten-week course, from the beginning to the end of the activities.

In Figure 1, CKP-scales are reported according to the results, from the higher mean to the lower.

Figure 1. Average score of the CKP-Questionnaire scales

When looking at the scales from top mean score to bottom, we can see that the top four scales have very similar high scores (from 4.2 to 4.1). Development through feedback is the skill perceived as the most acquired (mean $=4.2$ ), immediately followed by Learning to collaborate on shared objects $($ mean $=4.2)$. The last three scales are slightly 
under the average score of 4 - though, this is still to be considered as highly acquired with the last one referring to the Interdisciplinary collaboration and communication $($ mean $=3.5)$.

\section{The knowledge work skills perceived as most acquired at the end of each module}

To answer to the research question 2 (RQ2): To what degree do students believe they have acquired specific knowledge-work skills in relation to each specific module of the course? the SM questionnaire ( $\mathrm{N}=303$ questionnaires filled) was used.

Table 5 shows the average scores for each module, the average scores when the three modules are collapsed together, and the differences found when comparing the three modules by using ANOVA (value of $F$ and $p$ ).

[Table 5. Results from the SM questionnaire, near here]

Looking at the overall averages when the modules are collapsed (fourth column of Table 4), it is apparent that all of the 18 investigated abilities reached an average score higher than 2 on a three-point Likert-scale. Moreover, nine of the investigated abilities $(50 \%)$ scored more than 2.5. The abilities with a higher rank refer to social and technological aspects involved in the learning process: a) Considering others' point of view (2.9), b) Using social media to exchange information (2.8), and c) Collaborating to build products (2.7).

When considering the scores across the three individual modules, the abilities seemed to considerably grow from module 1 to module 3 . To test this, we performed an analysis of variance to determine whether the difference across the modules was significant. Results show that the difference was significant for 12 out of 18 abilities ( $p$ 
$<.05)$. Moreover, the post hoc tests for multiple comparison (Bonferroni), reported that each of the 12 abilities had a significant difference between module 1 and module 3 . For seven of them, there were significant differences also between module 1 and 2 .

Specifically, after module 2 students perceived that they had improved their abilities to work on collaborative products (N. $5, p=.002^{3}$ ), to face conflicts by seeking for possible mediations (N.7, $p=.005)$, to properly use theoretical references (N. 10, $p=.018$ ), to analyse and understand complex texts (N. 12, $p=.000)$, to search information on the Internet (N. 15, $p=.000$ ), to solve conceptual problems with the help of technologies (N. 16, $p=.012$ ), and to recognise a source reliability (N. 18, $p=.006$ ).

After the third module, a further five abilities were found to be significantly different when compared to module 1 . These were, producing clear and appropriate texts for the audience (N. 4, $p=.016^{4}$ ), integrating different information sources and several knowledge formats (N. 6, $p=.002$ ), defining own learning goals and the strategies to accomplish them (N.9, $p=.004)$, flexibly adapting to critical and unforeseen events (N. 13, $p=.016)$, and coordinating a work group to achieve common goals (N.14, $p=.003)$.

\section{Most appreciated aspects in each module}

For research question 3 (RQ3): Which aspect did the students appreciate the most in each module of the course, it was important to gain an insight into how specific features of a module could have impacted students' general appreciation of the course. To do this the SM questionnaire included an open-ended question: "What did you appreciate

\footnotetext{
${ }^{3}$ Significance of differences between module 1 and 2 after post hoc (Bonferroni)

${ }^{4}$ Significance of differences between module 1 and 3 after post hoc (Bonferroni)
} 
the most in the module just ended?". A qualitative content analysis was conducted on the responses gathered, applying the codebook previously described.

The following figure shows the total percentage assigned to each category, when considering the responses from all three modules (Figure 2).

Figure 2. The most appreciated aspects of the course

Responses from across the three modules indicated that the students' highest appreciation was for the learning topic (24\%), followed by the project-work (17\%), and the group participation (15\%). Learning strategies (13\%), debate (11\%) and groupworking (10\%) were also appreciated, whereas knowledge building (7\%) and unspecified aspects (3\%) were the less frequently mentioned aspects in students' responses.

By looking at the distribution of the categories in each module (Figure 3), the most appreciated aspects become more evident.

Figure 3. Most appreciated aspects at the end of each module.

In module 1, the learning topic (23\%: "I really liked to deal with themes such as specific learning theories, that is how children and youngsters learn, how the school works, how a good teacher should be to support learning and psychological growing too") and the debate (22\%: "I appreciated the opportunity we were given to express our thoughts on a particularly important topic and to listen to other points of view") are the most cited features. Students also appreciated knowledge building as a learning 
approach (14\%), their own group participation (14\%), and other specific learning techniques, such as building a conceptual map (13\%).

In module 2, the learning topic was again the most appreciated aspect, with a percentage more than twice as high when compared to module 1 (48\%: "The possibility of dealing with a concrete topic from everyday life yet considering those aspects that would not normally be taken into consideration"). Specific learning strategies were also more appreciated than in module $1(18 \%)$. The quality of groupmates' contribution was still appreciated (11\%), however, students did not consider the value of debate in the same way as in module 1 (6\% versus the $22 \% \%$ in module 1). Debate, group-working, and project-work all demonstrated similar levels of appreciation (6\% and 5\%).

In Module 3 the project-work was the most appreciated feature (52\%: "I particularly appreciated the possibility of externalising the concepts learned during the course while structuring of the project”). Students also appreciated their own group's participation (20\%: "Teamwork, the interdependence that has been created between me and my colleagues") and group-work (14\%). The remaining categories (five), when summed up, altogether reach $15 \%$ of the preferences, confirming the absolute predominance of the collaborative project-work in this module.

\section{Discussion}

When considering student perceptions - both at the end of the course and from each individual module - about their skills development, it would appear that the Trialogical Approach used to inspire the course design effectively promoted the targeted knowledge work skills, notably the capability to use feedback to improve the objects under construction. This skill is connected to the capability to work together in a very 
concrete way, going beyond the simple group dimension and focusing on the object development.

Useful information can be deduced when considering the significant differences that we were able to trace along the course. These can be outlined as follows:

a) Different modules had different impacts on students' perceptions of how their own skills had developed. This was mainly related to the specific activities of the considered module. During the first module, in which students were involved in knowledge-building discussions and in collaboratively creating a conceptual map, they perceived themselves to have strongly developed the ability to consider others' point of view and to collaboratively build products. The most rated skills after the second module were once again related to the activities just performed. These included, to read and discuss complex texts (scientific articles), to look for information on the Internet and assess its reliability, and to discuss and use that same information within the group while working on the first draft of the pedagogical scenario. Finally, in the third module, the abilities perceived as most developed were partially module-related, such as writing a good pedagogical scenario and integrating the various information previously collected. However, in other cases, the abilities were related to psychological and individual aspects of the learning process (i.e., defining learning goals and the strategies to accomplish them; and flexibly adapting to critical and unforeseen events). This latter result can be considered an unplanned, yet welcome, side-effect of the course, and possibly be due to the request for students to iteratively collaborate for many weeks, with strict assignments, timing, and constant assessment - not only by the teacher of the course but also by peers and external experts too.

b) Students' perceptions of mastering specific abilities grew throughout the course. This may have been a result of the course/modules' structure, but also may 
reflect students becoming more self-confident as the course progressed. The nonsignificant differences found for three of the 18 investigated abilities (to consider others' points of view, to use social media to exchange information, and to collaborate to build products) could be explained by the high values they had been assigned at the end of module 1, rendering the positive change from the start to the end of the course negligible. The other three non-significant abilities (to assess myself, to manage time to achieve my goals, and to take notes in an effective way), were not related to specific activities carried out during the course, instead relating to more general performance markers.

The answers to the open-ended question allowed us to grasp an insight about students' appreciation of some of the more specific aspects of the course. In module 1 students stated that they particularly appreciated the learning topic ("the good teacher" topic which is typical in a Pedagogy course) and the debate. Students may have felt at ease when discussing this topic because they could refer to their personal experience with teachers they had met during their own school career. Moreover, the peer-discussion provided them with further insights for discussion. In module 2, the learning topic was again the most appreciated aspect; students were involved in a discussion about the role of technologies in learning, reflecting on pros and cons. Once again, they dealt with a topic that was able to catch their attention and trigger an engaging discussion. Finally, in module 3 students attributed great value to the project-work activity, especially since it gave them the chance to show and put into action what they had learned. Furthermore, during module 3, the group's participation was particularly appreciated. By the end of the course, collaboration appeared to be a skill that had been mastered enough to make group work easier, more productive and more appreciated.

On the basis of the student comments, it would appear that our attempt to close the gap 
between theoretical information and its practical application into a real-life context was appreciated. Students recognised the advantages of working in groups and acquiring skills such as being flexible and integrating new learning strategies for the sake of achieving a common goal. This kind of pragmatic approach can be recognised transversally throughout our results and is in tune with the general scope of the course and the reasons why the trialogical principles were adopted. Our aim was to design a course that would be able to develop skills to connect the world of knowledge with the world of work and careers; in other words, how to put into practice what is learnt theoretically. Implementing the TLA has offered students the possibility to build a typical pedagogical tool (the pedagogical scenario) and to interact - directly or indirectly via email or a learning platform - with school professionals (teachers and principals). Overall, this was an exceptional opportunity for our students, who one day will be psychologists, to not only develop skills, competencies and knowledge, but to see knowledge applied in a real-world educational work-based context and to reflect on the consequences of such application.

\section{Conclusions}

In university teaching it is essential to prepare students for work with knowledge. As Ilomaki, Lakkala and Kosonen (2013) state, to be successful in the knowledge work society it is essential that students acquire knowledge work skills at the individual, social and epistemic levels. Few university courses, however, try to go beyond traditional teaching by putting students in front of genuine problems, and using technologies in an active and collaborative way. University methods of teaching remain rather transmissive, even when online teaching is introduced

The 'Experimental Pedagogy' course presented in this paper had been specifically designed to foster knowledge work skills for Psychology students. Both the 
complex architecture underpinning the course, as well as the data-collection, were inspired by the Trialogical Learning Approach and its six design principles, each promoting specific skills. In order to verify effectiveness of our trialogical design we collected data about students' perception of the acquired skills they gained and on what students saw as the most relevant features of the course.

Our results confirm the effectiveness of our trialogical design in promoting positive student perceptions of the knowledge work skills examined. In particular, students perceived that they had learnt how to use feedback to improve their products and how to collaboratively work on shared objects. These are two crucial skills in the knowledge work society reflected by two core activities during the course: (1) to collaboratively create knowledge objects and (2) to comment on each other's products to iteratively improve them. Students themselves confirmed the strong correspondence between specific learning strategies and the related skills, when they were asked to state which capability they had learnt after a specific module. That is to say that the way we had adopted to apply a design principle that succeeded in promoting the expected knowledge-work skills.

The interdisciplinary dimension was the skill that students reported having acquired to a lesser degree. It should be noted that in the first edition of the course the perception of students regarding the acquisition of this competence was lower than the average score of 3 (on a Likert scale of 1-5). In the following edition, the subject of this paper, the figure of the 'expert', namely a school or university teacher in the role of a supervisor for each group, was introduced. These 'experts' established the link with the world of work, in this case a school context, allowing students to interact with practices and methodologies associated with a community of teachers. Although not so highly 
rated as for other skills, students did perceive themselves to have acquired skills to work and interact with other professional communities (interdisciplinary dimension).

These results are useful in understanding how TLA and its design principles can help teachers to design university courses based on collaborative work and the creation of meaningful artifacts. These courses can help students to develop skills necessary to connect the world of knowledge with the world of work and careers; in other words, how to put into practice what is learnt theoretically.

Of course, we recognize this study has some limitation. For instance, we are aware that our sample is modest and culturally bounded to a specific context. In addiction, another limitation is that we analysed only students' perceptions. Going further with this research, the results here discussed are being reframed into a larger study where students' perception will be integrated with a finer analysis of the interactions and of the intermediate products. Therefore, the findings of this study should be viewed as a promising starting point for further larger-scale research aimed at further understanding the effects of TLA inspired university courses on the development of specific knowledge-work skills.

\section{References}

Aggarwal, R. 2011. "Developing a global mindset: Integrating demographics, sustainability, technology, and globalization”. Journal of Teaching in International Business 22 (1): 51-69. doi: https://doi.org/10.1080/08975930.2011.585920

Biesta, G. 2009. "Values and ideals in teachers' professional judgement". In Changing teacher professionalism, edited by Sharon Gewirtz, Pat Mahony, Ian Hextall and Alan Cribb, 184-193. Routledge: London.

Biesta, G. 2011. "Disciplines and theory in the academic study of education: A comparative analysis of the Anglo-American and Continental construction of the field". 
Pedagogy, Culture and Society 19 (2): 175-192. doi: https://doi.org/10.1080/14681366.2011.582255

Bruner, J. S. 1996. The Culture of Education. Harvard University Press.

Cazden, C. B., and Beck, S. W. 2003. "Classroom discourse”. Chap. 5 in Handbook of discourse processes, edited by Arthur C. Graesser, Morton Ann Gernsbacher and Susan R. Goldman, 165-197. Mahwah, NJ: Lawrende Erlbaum Associates, Inc., Publishers

Cesareni, D., Cacciamani, S., and Fujita, N. 2016. "Role taking and knowledge building in a blended university course". International Journal of Computer Supported Collaborative Learning 11(1): 9-39. doi: https://doi.org/10.1007/s11412-015-9224-0

Choi, I., Land, M.S., and Turgeon, A. J. 2005. "Scaffolding peer-questioning strategies to facilitate metacognition during online small group discussion." Instructional science 33: 483-511. doi: https://doi.org/10.1007/s11251-005-1277-4

Cole, M. 1996. Cultural Psychology: A Once and Future Discipline. Cambridge, MA: The Belknap Press of Harvard University Press

Delors, J. 1997. Nell'educazione un tesoro: Rapporto all'UNESCO della Commissione Internazionale sull'Educazione per il Ventunesimo Secolo. Armando Editore.

De Wever, B., Van Keer, H., Schellens, T., and Valcke, M. 2010. "Roles as a Structuring Tool in Online Discussion Groups: The Differential Impact of Different Roles on Social Knowledge Construction.” Computers in Human Behavior 26 (4): 516523. doi: 10.1016/J.Chb.2009.08.008.

Dewey, J. 1904. "The Relation of Theory to Practice in Education." In The Third Yearbook of the National Society for the Scientific Study of Education: Part I, edited by Charles A. McMurry, 9-30. Chicago, IL: The University of Chicago Press. https://archive.org/details/r00elationoftheorynatirich.

Chi, M. T. H. (1997). Quantifying qualitative analyses of verbal data: A practical guide. Journal of the Learning Sciences, 6, 271-315. 
Dillenbourg, P., and Hong, F. 2008. "The Mechanics of CSCL Macro Scripts." International Journal of Computer-Supported Collaborative Learning 3 (1): 5-23. https://hal.archives-ouvertes.fr/hal-00692019/document.

Engeström, Y. 1987. Learning by expansion. Helsinki: Orienta Konsultit.

Ilomäki, L., Lakkala, M., and Kosonen, K. 2013. "Mapping the terrain of modern knowledge work competencies". Paper presented at the at the 15th Biennial Conference for Research on Learning and Instruction (EARLI), August 27-31. University of Nicosia, Munich, Germany.

Hakkarainen, K., and Paavola, S. 2009. "Toward a Trialogical Approach to Learning." In Transformation of Knowledge Through Classroom Interaction, edited by Baruch Schwarz, Tommy Dreyfus, and Rina Hershkowitz, 65-80. Routledge.

Johnson, D., Johnson, R., and Johnson-Holubec, E. 1992. Advanced cooperative learning. Interaction, Edina, MN.

Johansson, K., Kopciwicz, L., and Dahlgren, L. O. 2008. "Learning for an unknown context: a comparative case study on some Swedish and Polish Political Science students' experiences of the transition from university to working life." Compare, 38(2): 219-231. doi:https://doi.org/10.1080/03057920701582764

Kolb, D. A. 1984. Experiential Learning: Experience as the Source of Learning and Development. FT Press.

Kong, S. C. 2014. "Developing information literacy and critical thinking skills through domain knowledge learning in digital classrooms: An experience of practicing flipped classroom strategy." Computers \& Education, 78, 160-173. doi: https://doi.org/10.1016/j.compedu.2014.05.009

Le Boterf, G. 1994. De la compétence. Essai sur un attracteur étrange. Edition d'Organization

Ligorio, M.B., and Sansone, N. 2009. "Structure of a Blended University Course: Applying Constructivist Principles to Blended Teaching." In Information Technology 
and Constructivism in Higher Education: Progressive Learning Frameworks, edited by Carla R. Payne, 216-230. Igi Idea Group Inc.

Mehan, H. 1979. Learning lessons. Cambridge, MA: Harvard University Press.

Mudrack, P. E., and Farrell, G. M. 1995. "An examination of functional role behavior and its consequences for individuals in group settings." Small Group Research, 26(4): 542-571. doi: http://psycnet.apa.org/doi/10.1177/1046496495264005

Muukkonen, H., Lakkala, M., Toom, A., and Ilomäki, L. 2017. “Assessment of Competencies in Knowledge Work and Object-Bound Collaboration During Higher Education Courses." In Higher Education Transitions: Theory and Research edited by Eva Kyndt, Vincent Donche, Keith Trigwell, and Sari Lindblom-Ylänne, 288-305. London, UK: Routledge.

Nicol, D., Thomson, A., and Breslin, C. 2014. "Rethinking feedback practices in higher education: a peer review perspective." Assessment \& Evaluation in Higher Education, 39(1), 102-122. doi: http://dx.doi.org/10.1080/02602938.2013.795518

OECD (2013). The Survey of Adult Skills: Reader's Companion. Paris: OECD Publishing. doi: http://dx.doi.org/10.1787/9789264204027-en

Paavola, S., and Hakkarainen, K. 2014. "Trialogical Approach for Knowledge Creation." In Knowledge Creation in Education, edited by Seng Chee Tan, Hyo Jeong So, and Jennifer Yeo, 53-73. Springer: Singapore. doi: https://doi.org/10.1007/978-981287-047-6_4

Paavola, S., Engeström, R., and Hakkarainen, K. 2012. "The Trialogical Approach as a New Form of Mediation". In Collaborative Knowledge Creation, edited by Anne Moen, Anders I. Mørch, and Sami Paavola, 1-14. SensePublishers, Rotterdam. doi: https://doi.org/10.1007/978-94-6209-004-0_1

Paavola, S., Lakkala, M., Muukkonen, H., Kosonen, K., and Karlgren, K. 2011. "The Roles and Uses of Design Principles in a Project on Trialogical Learning." Research in Learning Technology 19 (3). doi: https://doi.org/10.3402/rlt.v19i3.17112 
Paavola, S., Lipponen, L., and Hakkarainen, K. 2004. "Models of Innovative Knowledge Communities and Three Metaphors of Learning." Review of Educational Research 74 (4): 557-576. doi: https://doi.org/10.3102/00346543074004557

Rubin, K. H., Bukowski, W. M., Parker, J. G., and Bowker, J. C. 2008. "Peer interactions, relationships, and groups". Chap. 5 in Child and adolescent development: An advanced course, edited by William Damon, Richard D. Lerner, Deanna Kuhn, Robert S. Siegler, Nancy Eisenberg, 141-180. John Wiley \& Sons, Inc.

Sansone, N., Cesareni, D., Bortolotti, I., Mclay, K. (Under Submission). "Designing and re-designing a university course based on the Trialogical Learning Approach." In Teachers as Designers of TEL Interventions, edited by Donatella Persico, Francesca Pozzi, Peter Goodyear. British Journal of Educational Technology

Sansone, N., Ligorio, M. B., and Buglass, S. 2016. "Peer E-Tutoring: Effects on Students' Participation and Interaction Style in Online Course." Innovations in Education and Teaching International 55 (1): 13-22. doi: 10.1080/14703297.2016.1190296.

Scardamalia, M., and Bereiter, C. 1994. "Computer support for knowledge-building communities." The journal of the learning sciences, 3(3): 265-283. doi: https://doi.org/10.1207/s15327809jls0303_3

Scardamalia, M., and Bereiter, C. 2003. "Knowledge building environments: Extending the limits of the possible in education and knowledge work". In Encyclopedia of distributed learning, edited by Anna DiStefano, Kjell Erik Rudestam, and Robert J. Silverman. Thousand Oaks, CA: Sage Publications.

Scardamalia, M. 2004. “CSILE/Knowledge Forum ${ }^{\circledR}$ ”. In Education and technology: An encyclopedia, edited by Ann Kovalchick and Kara Dawson, 183-192. Santa Barbara: ABC-CLIO

Scardamalia, M., and Bereiter, C. 2007. "Fostering communities of learners and knowledge building: An interrupted dialogu"'. In Children's learning in laboratory and classroom context: Essays in honor of Ann Brown edited by Joseph Campione, Kathleen Metz, Annemarie Sullivan Palincsar, 197-212. New York and London: Routledge. 
Scardamalia, M., Bransford, J., Kozma, B., and Quellmalz, E. 2012. New assessments and environments for knowledge building. In Assessment and teaching of 21 st century skills, edited by Patrick Griffin, Barry McGaw, Esther Care, 231-300. Springer, Dordrecht.

Sfard, A. 1998. "On Two Metaphors for Learning and the Dangers of Choosing Just One.” Educational Researcher 27 (2): 4-13. doi: 10.3102/0013189X027002004

Slavin, R. E. 2010. “Co-Operative Learning: What Makes Group-Work Work.” The Nature of Learning: Using Research to Inspire Practice: 161-178. doi: 10.1787/9789264086487-9-En

Strijbos, J. W., and De Laat, M. F. 2010. "Developing the Role Concept for ComputerSupported Collaborative Learning: An Explorative Synthesis." Computers in Human Behavior 26 (4): 495-505. doi: 10.1016/J.Chb.2009.08.014

Topping, K. J. 2005. “Trends in peer learning.” Educational psychology, 25

(6): 631-645.doi: https://doi.org/10.1080/01443410500345172

Vygotskij, L. S. 1981. "The Genesis of Higher Mental Functions". The Concept of Activity in Soviet Psychology, 144-188. Sharpe, New York. https://people.ucsc.edu/ gwells/Files/Courses_Folder/documents/VygotskyHigherMF.p df

Webb, N. M. 1985. "Student Interaction and Learning in Small Groups.” In Learning to Cooperate, Cooperating to Learn, edited by Robert Slavin, Sholmo Sharan, Spencer Kagan, Rachel Hertz-Lazarowitz, Clark Webb, and Richard Schmuck, 147-172. Plenum Press: New York. doi: https://doi.org/10.1007/978-1-4899-3650-9_6

Wenger, E., Trayner, B., and De Laat, M. 2011. "Promoting and Assessing Value Creation in Communities and Networks: A Conceptual Framework." The Netherlands: $\begin{array}{llll}\text { Ruud De } & \text { Moor } & \text { Centrum }\end{array}$ https://www.ou.nl/Docs/Expertise/RdMC/2011\%20Rapporten/WEB_Rapport\%2018_A ssessment\%20framework_DEF.pdf 